\title{
Organizational and technological systems for renovation of production facilities
}

\author{
Dmitriy Topchiy ${ }^{1, *}$ \\ ${ }^{1}$ Moscow State University of Civil Engineering, Yaroslavskoe sh. 26, 129337 Moscow, Russia
}

\begin{abstract}
The article describes the stage of construction - one of the main compulsory periods of the life cycle in the formation of construction endproducts. It is at this particular stage that actual reliability and safety indicators of capital construction projects (specified at the design stage) are formed determining the parameters of operational, functional and economic efficiency. The compulsory assessment of conformity of buildings and structures, as well as design (including survey), construction, installation, setting up, and recycling (demolition) processes associated with buildings and structures is conducted in different countries in the form of state construction supervision. An assessment results in a document certifying conformity of the actual indicators with the requirements of design, normative (industrial) and legislative documents. Conformity is assessed in accordance with procedural rules depending on the functional purpose of the capital construction project. There are two conformity assessment forms that appear to be similar (at first glance): "construction inspection" and "state construction supervision". Similarity of these terms lies in the fact that they both characterize a resulted approach used to assess the conformity of activities of participants in the construction operations (customers, developers, contractors) on the formation of construction end-products - construction projects.
\end{abstract}

\section{Introduction}

Industrial zones in Moscow occupies area of approximate 20 thousand hectare, that is equal to one fifth of the total area of the city. The main trend of Moscow, as the leader of Russian cities actively implementing programs of renovation of such zones, is the development of such zone in two main directions: without changing functional purpose of the territory, when such industrial sites are re-profiling in an innovation, knowledgeintensive, having no ecological impact factories, but having same function, or with functional change of territory, which basically means demolition of buildings and reclamation of soil

Developing such industrial areas, the city authorities create new working places in immediate proximity to the place of living of local people in the periphery of the city area.

This approach also helps to solve some of logistic issues in the city. Since traffic in the morning rush hours will be directed towards direction from the central part of the city and

* Corresponding author: aljurgaitis@gmail.com ; 89161122142@mail.ru 
in the evening from the suburbs to the city center. Because of this, city transport infrastructure has significant decrease of traffic congestion and more dynamic logistic transport schema are created. All these aspects provide possibility of using territories located far outside from megalopolises.

Redevelopment of industrial city areas creates base for development of big number projects for residential blocks construction, consequently, this process gives possibility for further development of new social facilities, transport networks and recreational green areas. For instance, there are plans in Moscow for renovating areas with total surface area of almost 15 thousand hectares. 5 thousand hectares out them will go through total demolition of all buildings, reclamation of soil and further construction. Another 8 thousand hectares will undergo to the renovation partly. Some buildings will be reconstructed or reprofiled for social needs of the local population, partly solving highly demanding issues of the city - new sports centers, additional parking lots, entertainment city centers, movie theaters and so on.

However, the processes, connected with the renovation projects and reassignment of industrial buildings, lack the system approach. This issue causes the big amount of additional production costs, as well as decrease of economic efficiency and technological safety during the realization of such projects.

The main principals of the "system approach" and "era of system" in scientific activities of savants of our country began to be created in the middle of the last century. They were based not only on explaining of scientific events by the great scientist of our country like Mikhail Lomonosov, Dmitry Mendeleev, Ivan Michurin, Nikolay Vavilov, Konstantin Tsialkovskiy, Vladimir Ginzburg, Lev Landau and many others, but also based on works of many leading foreign scientists from various scientific fields: Peter Weiss, William Ross Ashby, Ludwig von Bertalanffy, Mikhailo Mesarovich.

One of the key scientists, who was formulating the scientific activity on the systemmatrix principle was Niels Bohr. In his work concerning the quant theory of hydrogen like atom, he was based on the system approach, explaining by it the fine structure of spectral lines. He also formulated "The Rule of Choice" using it further for the principle of harmonic oscillator. Later this correspondence principle played one of the main roles in creating of progressive quantum mechanics, which in its turn formed "The system of interactions". Such approach to the study of the questioned structure gives enlarged possibilities to notice going interactions and build them according to unified principle.

In contrast to phenomenological approach proposed by Niels Bohr, Albert Einstein, in his term, tried to form such systems, which allowed describing processes and changes going within it, and on top of it, allowed the system to change dynamically by influence of inner factors as well as by influence of the environment, but staying stable at the same time [1-6].

The main difference in the approaches of Niels Bohr and Albert Einstein is their attitude towards to the formulating of the gist of the system. Phenomenological approach gives understanding about how the elements of the system interact. The methodology of Einstein helps to understand links within the system in empirical way and create them in logical necessity. These two great scientists determine the creation of the structure as the united structure of the holistic approach towards oneness.

The word "System" is ancient one (it comes for ancient Greek word $\sigma 0 ́ \sigma \tau \eta \mu \alpha$ - unified, something which consists of parts, compound) and is used to describe in the context of separate elements joined together according to unified principals, however the unified requirements, criteria and frames of functioning as well as structures of interconnections frequently miss.

The main attribute of the system approach is analytical study of a separate object, in this case, it is the industrial site area which will go under renovation, without precise forming of 
the separate element of this system, the modules and units the system consist of and interconnections within it and with the ambient environment. [7].

One of the first Russian scientists who started to study processes, appearing during the realization of different construction projects, was Professor, doctor of technical science Alexander Gusakov. He was the creator of the school "System-technic in construction".

$\mathrm{He}$ not only formulates the terminology and principles of the system approach for studying different processes, but also creates criteria and principals of interconnections and responses creating the connections

\section{Materials and methods}

During creating unified criteria of choosing elements of the system for realization of a project for renovation and reassignment of industrial objects, 4 main phases were found.

On the first stage, we must understand social and business orientated elements of the newly created system. These elements includes the attitude of the social groups towards the project of the re-profiling of a site, then the attitude of the state, represented by differing authorities and governmental bodies.

During the second phase, it is important to create mathematically connected network of links, criteria and responses on internal and external signals. Then we need evaluate and form possibility of the structure to develop, provide tools for comfortable entering of information and receiving of operational responses. We need to evaluate the level of influence from outside and guarantee resilience during different conditions of functioning.

The third stage of the forming of the system approach towards rearranging of industrial areas must guarantee that this system can be used for different projects, which are connected with renovation of industrial areas

The final fourth stage is measurement of system performance, understanding and development of the critical ways for the project realization, evaluation of level and criteria of efficiency of the system.

In this way, it is obvious that for creation of system approach towards process of renovation and rearrangement of industrial areas, it is important to understand and formulate the fundamental system creating factor. The finding of this factor is the moment of the understanding of the System. This factor is used in scientific-research work devoted to development of unified system of rearrangement of industrial objects and areas.

The main features of the such formed system is the number of status.

- Theoretically formulated system can become general, if it connects all participants, all isomorphic regularities of the process and mechanism of interaction for the different modules of the system

- Finding of isomorphisms of the different modules of the system can be evaluated if the criteria of isomorphism is important and meaningful. The amount of criteria can calculated and mathematically analyzed.

- When creating "General Theory of system", it is necessary to find and describe the system-forming isomorph factor.

The system of organization and technologies for rearrangement of industrial objects, as well as any other system describing interconnections of participants in construction processes is based on mathematical theory of systems. The system itself is used not only for researches of the processes going during the realization of the project, but also for explanation of the different processes. The idea of realization of the mathematical models was detailed described in the works of Mekhailo Mesarovich. He formulated the order of using of mathematical model during the studying of characteristic of the researching model 
(method of deduction) or by using of computer simulating. Thus, the methodology of the system approach has the following structure.

- Formulization. Forming of the system according to the technical task

- Deduction. The research of the formed system.

- Interpretation. Study of the received results of provided by the system

So the sequence of using of mathematical theory in the structure of organization system of interaction of participants of rearrangement process, is done by the following principle: theoretical forming is done in the beginning, then it is used and check on one of the real object, then the received results and other events are evaluated.

The mathematical model is designed for assessing the state (quality and established design parameters) of the construction operations system (preparatory, main, final construction stages). The model is based on the concept of probability of the construction operations system (associated with a particular construction project) being (at any arbitrary point of time) in any of the accepted states (Figure 1).

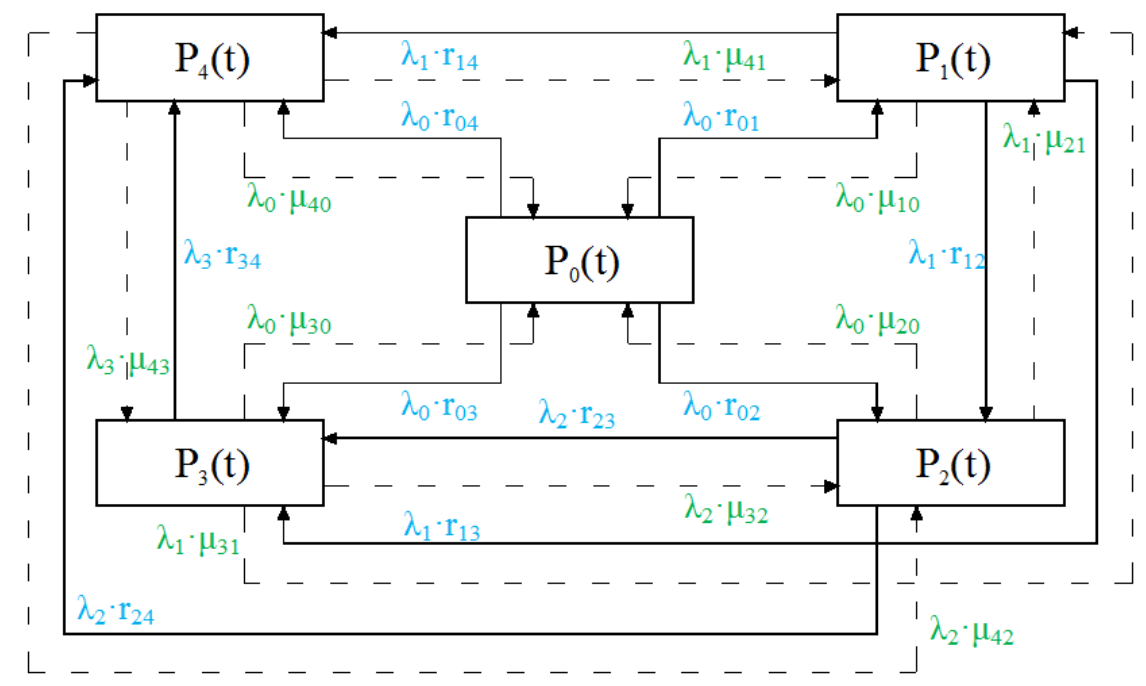

Fig.1. A graph of accepted states of the construction operations system.

Result [9-10]:

Possible states of the system (model) are identified as:

- The expected (designed) conditions of the functioning of a construction operations system (the standard quality of implementation of a construction project) - state $\mathrm{P} 0(\mathrm{t})$;

- Minor deviations (from the designed conditions) in the conditions of functioning of a construction operations system (an acceptable quality of implementation of a construction project) - state $\mathrm{P} 1(\mathrm{t})$;

- Noticeable deviations (from the designed conditions) in the conditions of functioning of a construction operations system likely to result in a certain deterioration in the quality of construction products, but acceptable in terms of safe operations (a satisfactory quality of implementation of a construction project) - state $\mathrm{P} 2(\mathrm{t})$;

- Regular (systematic) deviations (from the designed conditions) in the conditions of functioning of a construction operations system likely to result in deterioration in the quality of construction products that is acceptable in terms of safe operations with considerable limitations (an unsatisfactory quality of implementation of a construction project) - state P3(t);

- Regular (systematic) deviations (from the designed conditions) in the conditions of functioning of a construction operations system resulting in irreparable deterioration in the 
quality of construction products that is unacceptable in terms of safe operations and requires mothballing or demolition (a critical quality of implementation of a construction project) - state $\mathrm{P} 4(\mathrm{t})$.

Parameters $\lambda, \mu$ and $r$ are quantity values that represent transition of the construction operations system between the determined states.

For example, parameter $\lambda$ represents the possibility of installing a structural unit in the designed position with unacceptable deviations (deterioration in the quality of construction products), while parameter $\mu$ represents the possibility of rectification of unacceptable deviations in a structural unit revealed by control measurements.

The quality values of parameters $\lambda, \mu$ and $r$ can be ascertained by various means, for example, statistical processing of frequency of occurrence of corresponding negative factors (unfavorable atmospheric factors, construction equipment malfunctioning, construction personnel errors, design errors, "malfunctioning" structural units - the number of factor groups under review can be arbitrary). The whole process of construction (mathematical model functioning) is described by a differential equation system.

Initial conditions are as follows:

$$
\mathrm{P} 0(\mathrm{t})=1, \mathrm{P} 1(\mathrm{t})=\mathrm{P} 2(\mathrm{t})=\mathrm{P} 3(\mathrm{t})=\mathrm{P} 4(\mathrm{t})=0
$$

Analysis (using the proposed mathematical model) results in distribution of probabilities between possible states.

For example, Figure 3 shows the results of distribution of probabilities of the state of a construction operations system (with certain initial values of parameters $\lambda, \mu$ and $r$ and relationship (1) for the term of construction equal to 281 working days.

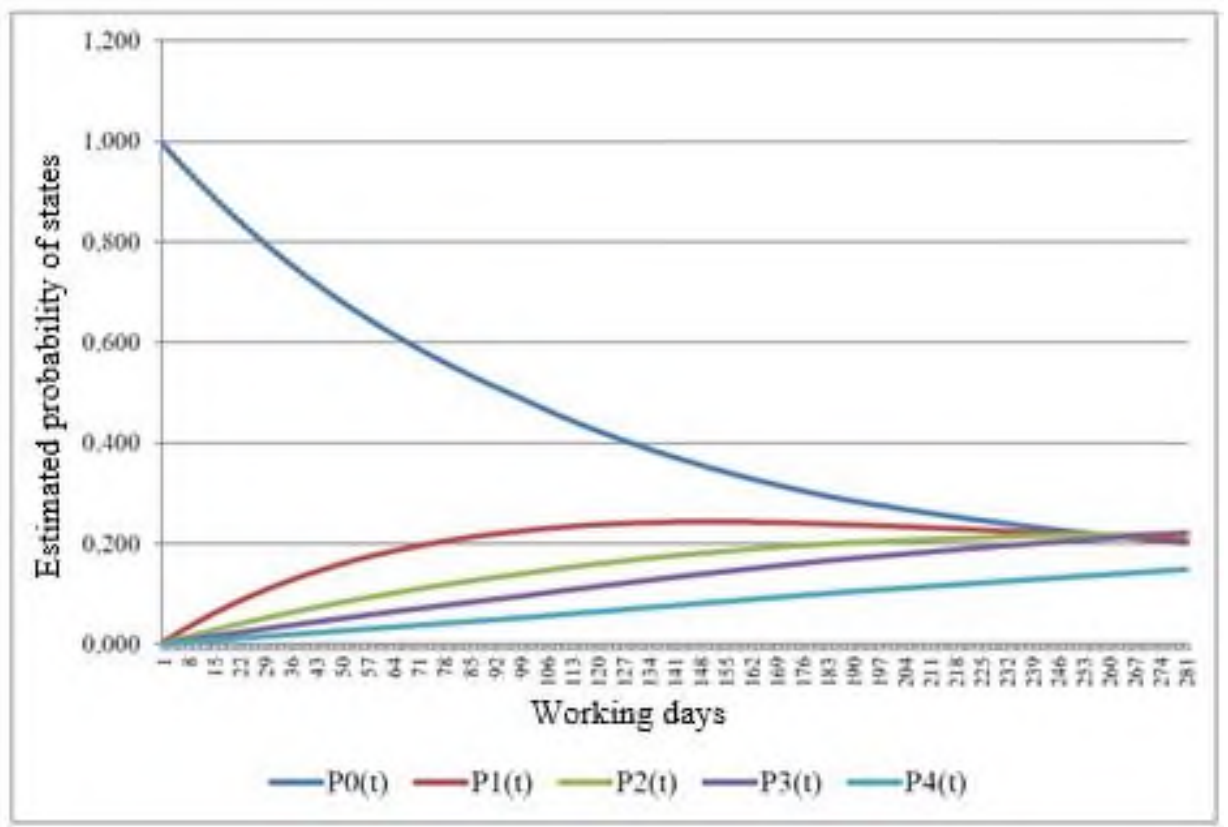

Fig.2. Distribution of probabilities between states of a construction operations system. An estimated value of the probability of a state of a construction operations system can be linked to construction risk assessment by a relationship as follows: $\mathrm{R}=\mathrm{Pi}(\mathrm{t}) \cdot \mathrm{F}$ where:

$\mathrm{R}$ - quantitative value of the risk of deterioration in the quality of construction products;

$\mathrm{Pi}(\mathrm{t})$ - estimated value of the probability of a state of a construction operations system;

$\mathrm{F}-$ quantitative value of the function of the severity of consequences (risks). 


\section{Results and Discussion}

The received result must be thoroughly analyzed as the main element of the system activity. It is very important to represent all activity of the system as well as different received variation rows in different terminological results, highlighting the importance of mathematical model. This influence can be shown by the following points.

1) Kind and type of the awaiting results

2) The phases of received results

3) The element (module) outstanding result.

4) The evaluation of faithfulness of the received results

All above mentioned thesis are expressed by the main key mechanism of the system.

It is important to pay attention that the main element of organizational and technological system of rearrangement of an object are the informatioal flow and organizational structures. They can have different element creating modules, from which they consist. It is also needed to be said that one of the most important characteristics of the system is possibility of freedom of the modules as well as the element of the system in general, and the system in total accordingly. Since without such understanding and formalizing of the level of freedom of a element, it will be impossible to evaluate the modules itself and understand if they work correctly or not. The information received from it will be excessive, and it will be impossible to structure it or work with it. So the modules with such freedom, but not giving important results must be deleted.

\section{Conclusion}

In this way, the received result is the main and undetectable element of system functioning. The result provides possibility to the managing influence on the different elements and modules of the system. When the elements are working in this way, the system is called functional.

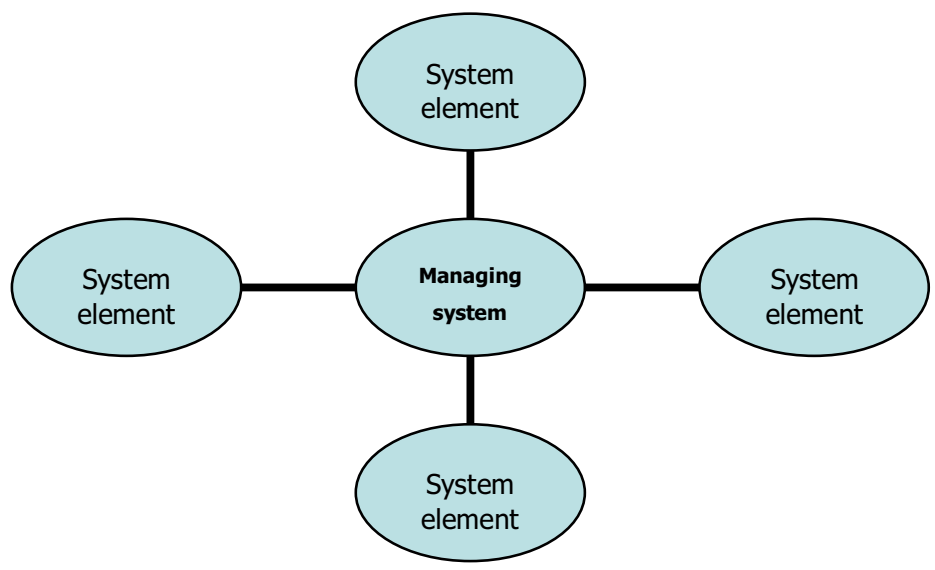

Fig. 3. Functional elements

Therefore, there is possibility to claim that the managing system is based on the managed object, which is beyond it and is located outside the system boarders.

Dialectical term "Managing system" means that it is whole and self-enough. 


\section{References}

1. M. Rogalska, W. Bozejko, Z. Hejducki, Automation in Construction, 18, 24-31, (2009) doi:10.1016/j.autcon.2008.04.002

2. P. Oleinik, A. Yurgaytis, MATEC Web of Conferences, 193, 05010, (2018) https://doi.org/10.1051/matecconf/201819305010

3. P. Oleinik, A. Yurgaytis, MATEC Web of Conferences, 117, 00130, (2017) https://doi.org/10.1051/matecconf/201711700130

4. I.L.Abramov, A.A. Lapidus, E3S Web of Conferences 33, 03066, (2018) https://doi.org/10.1051/e3sconf/20183303066

5. I. Abramov, HRC 2017 (HIGH-RISE CONSTRUCTION-2017) E3S Web of Conferences, 33, 03075 https://doi.org/10.1051/e3sconf/20183303075

6. A. Lapidus, I. Abramov, MATEC Web of Conferences, 193, 05033 (2018) https://doi.org/10.1051/matecconf/201819305033

7. A. Lapidus, I. Abramov, IOP Conf. Ser.: Mater. Sci. Eng. 365, 062002 (2018) https://doi.org/10.1088/1757-899X/365/6/062002

8. D. Topchiy, A. Tokarskiy, MATEC Web of Conferences, 196(1), 04029, (2018) https://doi.org/10.1051/matecconf/201819604029

9. D. Topchiy, A. I. Shatrova, International Journal of Mechanical Engineering and Technology, 9, 539-547, (2018)

10. D. Topchiy, A. Tokarskiy, IOP Conference Series: Materials Science and Engineering, 365, 062005, (2018) https://doi:10.1088/1757$899 \times / 365 / 6 / 062005$ 